\section{CARTOGRAFIAS SOCIAIS E TERRITÓRIO}

Henri Acselrad (Org.)

Instituto de Pesquisa e Planejamento Urbano e

Regional, 2008

Ana Maria Daou

Professora do Departamento de Geografia e do Programa de Pós-graduação em Geografia/IGEO/UfRJ

Cartografias sociais e território é o título da coletânea organizada por Henri Acselrad, pesquisador do Instituto de Planejamento Urbano e Regional IPPUR/ UFRJ, vinculado ao Laboratório Estado, Trabalho, Território e Natureza ETTERN/IPUR/UFRJ. Lançada no final do ano de 2008, reúne artigos que trazem a público reflexões que entrelaçam temáticas contemporâneas expressivas de processos de transformaçóes pelos quais vem passando, desde os anos 1970, a produção de mapas e de representações espaciais. O tema é vasto e sua complexidade amplia-se em face da crescente difusão das novas tecnologias de informação geográfica, disseminadas em experiências inovadoras por todo o mundo nos últimos vinte anos.

Os artigos reunidos no pequeno volume que inaugura a coleção, cujo título relaciona território, ambiente e conflitos sociais no Brasil, não tratam da discussão da cartografia em sua acepção usual, qual seja, o "conjunto de estudos e operações científicas, técnicas e artísticas que orienta trabalhos de elaboração de cartas geográficas", como consta na primeira acepção do dicionário Houaiss (2001). Tampouco é possível dizer que versam sobre mapa como "representação gráfica e convencional, em papel, cartolina, tela etc. dos dados referentes à superfície do globo terrestre, a uma região dessa superfície, à esfera celeste; carta geográfica” (idem). O propósito da publicação é revelar um conjunto de questōes e reflexōes relacionadas aos mapeamentos participativos que, no Brasil, em que pese sua diversidade, têm sido denominadas de cartografia social. Assim, o sugestivo epíteto especifica e circunscreve uma outra modalidade de cartografia em que sujeitos e coletividades se colocam não apenas ou não mais como usuários de mapas, mas como "fazedores de mapas" e intérpretes de suas cartografias.

Como indica Acselrad, as cartografias sociais delineiam um subcampo da cartografia, e este se particu- lariza pela ênfase na participação de não-especialistas nos processos de elaboração de mapas. Um vasto conjunto de experiências contemporâneas de mapeamento, embora se diferenciem pelas metodologias utilizadas, pelos arranjos institucionais e financeiros e pelos objetivos que encerram, abandona a perspectiva usual em que os mapas eram objetos acabados, utilizados para consulta. Nesses processos, os grupos que ocupam as áreas a serem mapeadas vêm a tornar-se parte ativa e interessada na elaboração de cartas, no levantamento de recursos, na definição de limites territoriais, entre outras temáticas contempladas pelas cartografias sociais. $\mathrm{O}$ resultado são mapas, em papel ou em base digital, que carregam inúmeros potenciais, inclusive o de poderem ser frequentemente atualizados e reelaborados na proporção em que se ampliam as legendas e se alteram as referências espaciais neles inseridas, constituindo cartografias dinâmicas ou situacionais.

A apresentação e o capítulo introdutório da coletânea situam a atualidade do tema e enfatizam particularidades assumidas pela temática no Brasil. "Distintos processos de disputas e equacionamento de conflitos na Amazônia brasileira têm se configurado como políticas públicas" e, nestes casos, o reconhecimento do território, a delimitação do uso dos recursos naturais ou as negociações relativas à demarcação de unidades de conservação e diversas territorialidades concorrentes têm certamente se favorecido das novas modalidades de cartografia.

A coletânea apresenta a reflexão de nove autores estrangeiros - em sua maioria geógrafos - inseridos em instituiçôes de ensino e pesquisa de universidades americanas e europeias (francesas e suíça). Nesses ambientes acadêmicos, desenvolveram-se debates e iniciativas efetivas que favoreceram a democratização das tecnologias de informação geográfica correlatas a mudanças significativas nos processos de consecução de mapas e sua utilização através dos Sistemas de Informação Geográfica. Essas mudanças tanto facilitaram quanto tornaram complexa a tarefa de mapeamento de processos sociais de expressão espacial. Os artigos trazem uma reflexão crítica sobre experiências ocorridas em realidades distintas e expressivas de disseminação das novas tecnologias de informação por todo o mundo.

Desta forma, os artigos disponibilizados no livro Cartografias sociais e território mostram o "estado da arte" em relação ao aprimoramento e ao uso "social", 
"participativo", da cartografia ancorada nas tecnologias digitais. Seja no contexto internacional, seja no contexto nacional, é significativo que desde as primeiras experiências de mapeamento participativo tenha sido recorrente a mobilização de diferentes esforços por parte de universidades, agências dos governos e organizações não-governamentais.

Assim, os avanços tecnológicos assumiram uma importância primordial para o desenvolvimento de um novo modo de fazer cartografia. Tanto houve uma profusão das imagens do conjunto do planeta quanto uma ampliação espetacular do uso das tecnologias que vieram facilitar, estimular e democratizar a produção de mapas e imagens de lugares outrora remotos ou de parca visibilidade. Os SIGs (Sistemas de Informação Geográfica) e os GPS (Global Positioning System) - cujo acesso foi difundido para além das universidades nos anos 1990 - têm possibilitado uma significativa ampliação do uso dos mapas e de sua apropriação, as mais distintas e inovadoras, seja por instituiçōes do governo, seja por ONGs e grupos sociais subalternos que, munidos de seus mapas, se veem capacitados a negociar e a reivindicar terras e recursos.

Sheppard, do Departamento de Geografia da Universidade de Minnesota, apresenta a trajetória do que veio a ser o SIG crítico como resultado da combinação de forças e interesses de profissionais conhecedores dos SIGs e aqueles identificados com a teoria social na geografia humana. A implantação de um programa de pesquisa que envolveu profissionais das duas áreas possibilitou uma profícua interlocução entre os desconfiados profissionais. Resultaram daí significativos avanços para a criação de contextos em que o software do SIG viesse a se tornar parte de um processo decisório democrático, com a anexação de informaçôes locais, com adicionais que permitiram a incorporação de outras mídias aos softwares.

Desde então tem sido crescente o uso das tecnologias de informaçōes geográficas para os mais diversos fins na sociedade contemporânea. São cada vez maiores as demandas de grupos sociais subalternos no sentido de se "inserirem" no mapa, delimitarem seus territórios e darem a conhecer seus espaços vividos. Há inúmeros relatos de mapeamentos participativos em contextos africanos, asiáticos e, embora predominem as ações entre populaçôes camponesas ou em sociedades tradicionais, são também significativas as experiên- cias de uso das novas tecnologias em contextos urbanos, seja no planejamento do território, seja no levantamento dos patrimônios identitários.

A coletânea promove uma refinada reflexão sobre os desdobramentos das novas formas de produzir mapas com inúmeras resoluçōes, cartogramas, mapas em mídias digitais, automapeamentos a serem posteriormente georreferenciados entre outros resultados, assim como traz inúmeras questōes teórico-metodológicas relacionadas ao uso participativo de tecnologias de informação geográfica. Apresenta experiências levadas a termo em outros países, as quais estimulam a comparação com os casos brasileiros. São significativos os exemplos contemporâneos de "populações tradicionais" - outrora fadadas ao silêncio ou ao congelamento no tempo e no espaço como efeito do progresso do país - que ganham voz e preenchem, a partir de seus referenciais, o mapa do Brasil com novas legendas. O acesso às tecnologias de informação, favorecido pela atuação de organizaçōes não-governamentais e pela implementação de projetos ligados às universidades, tem lhes permitido fazer frente à disputa pelo território, que resulta da expansão da fronteira e das dinâmicas territoriais recentes que incorporam os recônditos do país aos fluxos e às redes nacionais e internacionais.

Levy problematiza o valor do mapa na sociedade contemporânea em que a mobilidade crescente das populações e as dinâmicas do presente remetem a ideias de "espaços descontínuos", de territórios parcialmente recobertos, ou de espaços que se superpõem sem que necessariamente se comuniquem, como são propostas as articulaçōes entre territórios e redes. Tais fenômenos questionam a cartografia ancorada na métrica euclidiana, ao mesmo tempo contínua, contígua e uniforme, e promovem o desafio relativo à inclusão no mapa de geografias dinâmicas de referenciais simbólicos superpostos nas paisagens cotidianas.

A coletânea, além das contribuições específicas, tem o mérito de trazer para o público brasileiro a seleção e a tradução de artigos que, em conjunto, levantam inúmeras e complexas questões relativas ao uso da cartografia articulada às tecnologias de informação geográfica. O fenômeno nas últimas quatro décadas tem alterado as características e o papel dos mapas na sociedade contemporânea, tema cujo interesse tem sido redobrado através de diversas experiências no caso brasileiro, e que tem possibilitado o empoderamento de 
diferentes grupos sociais, como quilombolas, grupos indígenas, populações tradicionais. É crescente a mobilização de esforços institucionais e de coletividades no sentido da utilização dos SIGs e das tecnologias de informação em diferentes contextos sociais, iniciativas estas que, de modo crescente, vêm dando suporte às disputas por terras, ancorando reivindicações de garantias de acesso aos recursos naturais ou reivindicando a manutenção dos patrimônios identitários.

No Brasil, a discussão reflexiva sobre o uso das tecnologias de informação geográfica associada aos processos decisórios que privilegiam a participação de agentes sociais no uso dos SIGs tem sido reduzida. Os casos apresentados por Acselrad e Coli sobre cartografias sociais, mapeamentos participativos, ou o simples uso de mapas convencionais no âmbito de um processo de negociação têm se favorecido da atuação de antropólogos e sociólogos. Neste sentido, a participação de geógrafos e cartógrafos nas equipes e na produção da reflexão sobre os processos em jogo vem sendo pouco evidenciada, e isso vale também para as discussões teórico-metodológicas relacionadas ao uso das cartografias participativas.

A cada artigo se segue uma rica bibliografia que disponibiliza para o leitor brasileiro uma vasta seleção de trabalhos - em inglês ou em francês - de autores, perspectivas da produção e reflexão sobre os usos sociais das tecnologias de informação na elaboração de mapas. A produção sobre o tema remonta aos anos 1970, e é notável o crescimento dos títulos nos anos 1990, quando o uso dos SIGs e do GPS se disseminou mundialmente. É significativo o avanço da discussão teórica e metodológica sobre as potencialidades e as restrições promovidas pelo uso das tecnologias de informação geográfica em experiências no campo e nos contextos urbanos em âmbito internacional. São variados os trabalhos sobre o uso dos recursos entre populações autóctones, mapeamento de recursos naturais, gestão de águas e uso da terra, entre outras temáticas contempladas. A avaliação da dimensão da participação e da gestão do território, do meio ambiente, ou ainda as cartas multimídias no debate de políticas públicas e o uso dos SIGs no ensino da geografia contemplam sugestivo conjunto de questôes, como sugerem os títulos em francês.

Com as tecnologias de informações geográficas, os mapas passaram a ter como suporte o meio magné- tico, que ampliou de forma inédita a inclusão de múltiplas variáveis em um mesmo mapa. No entanto, as questôes suscitadas pelos mapeamentos participativos sugerem que uma de suas riquezas ou potencialidades reside sobretudo nos processos desencadeados, sejam os de elaboração das cartas, sejam os procedimentos que permitem o levantamento de variáveis socialmente relevantes e, ainda, as negociaçōes que o desenho dos mapas oferece. Muitas vezes, na ausência de políticas públicas, os projetos de mapeamentos participativos tornam-se oportunos para que as populações mapeiem recursos e necessidades expressas na multiplicidade das legendas ou traduzidas por meio de reivindicações junto às agências do governo.

Cartografias apoiadas por computador contribuíram enormemente para a profusão dos mapas e para a utilização crescente destes recursos, de tal forma que cada indivíduo possa se situar no mundo, reconhecer o seu chão na superfície do planeta ou viajar por sua vizinhança a partir de uma imagem do Google Earth. Naturalizam-se assim os procedimentos de projeção espacial ancorados nas coordenadas geográficas e a capacidade de se situar em relação aos outros. Tais processos ganham enorme complexidade ao envolverem populações até então distanciadas das formas letradas e científicas de representação espacial, ou mesmo por abarcarem sujeitos não familiarizados com a projeção bidimensional do espaço ancorada nas coordenadas geográficas. Os recursos tecnológicos parecem promover um atalho, e são de mais fácil apreensão que os mapas tradicionais.

A diversidade de experiências entendidas como cartografias sociais ensejam questóes relativas ao potencial de mobilização carreado por esses processos, que podem estimular o surgimento de novas assimetrias sociais. Em sua positividade, a atuação de populaçôes locais nos processos de mapeamento tem estimulado afirmaçōes identitárias, traduzidas na ideia de empoderamento, e parece promover um suporte para a elaboração de uma narrativa sobre o espaço, o território, a paisagem. Narrativas estas apoiadas nos referenciais compartilhados pelos sujeitos envolvidos nas oficinas e nos processos de consecução das novas cartografias. Neste sentido, não se trata apenas de se inserir no mapa ou de ser inserido no mapa, mas de se inscrever no mundo.

Diversas iniciativas que propõem a inclusão de populações locais nos processos cartográficos têm se 
disseminado mundialmente desde os anos 1990. No Brasil, conforme o balanço apresentado por Acselrad, já no final dos anos 1980, é possível reconhecer três processos significativos para o notável aumento do mapeamento participativo entre os anos de 2005 e 2007. É exatamente na Amazônia que um maior número de experiências vem ocorrendo, e através delas, novas territorialidades se delineiam no mapa da região. $\mathrm{O}$ caso da Reserva de Mamirauá, em 1992, expressa as demandas e negociaçôes relacionadas ao mapeamento de áreas protegidas, vinculadas ao sistema nacional de unidades de conservação; uma outra situação pioneira foi a delimitação de terras tradicionalmente ocupadas, como é o caso das reservas extrativistas, e um terceiro exemplo paradigmático é o caso da Grande Carajás, em que um enorme mapa - originalmente em suporte de papel, que depois foi ampliado para ser mostrado à população durante uma audiência pública-, permitiu que parte da população envolvida fortalecesse sua luta com vistas à garantia da posse e ao acesso aos recursos naturais.

Embora sejam numerosas as experiências e os projetos realizados junto a populações situadas sobretudo na Amazônia, fixadas no campo e envolvidas em processos de demarcação de territórios tradicionalmente ocupados ou de unidades de conservação, no contexto brasileiro não estão de todo ausentes as experiências que privilegiam a inserção de populações urbanas em processos de planejamento e gestão territorial participativos. Nos dois contextos, os processos de elaboração de cartografias sociais relacionam-se a disputas territoriais e a disputas cartográficas, pois, como indicam Acselrad e Coli, mapas são "abstraçōes do mundo" comprometidas com algum ponto de vista.

Se as cartografias sociais se ancoram em longa cadeia de recursos tecnológicos e abstraçôes que permitem aos sujeitos sociais se perceberem em um conjunto mais amplo, partem invariavelmente da representação do espaço próximo, conhecido - cujos limites são mediados pelas práticas e pelos saberes daqueles que interagem com as equipes detentoras do conhecimento técnico nas etapas de levantamento dos dados, no registro e no georreferenciamento, ou ainda, na leitura pública dos mapas tradicionais, como sugerem os relatos das experiências brasileiras apresentadas na coletânea. Assim, as implicações que as cartografias sociais promovem internamente nos grupos onde são produzidas merecem o tratamento analítico. Se muitos dos projetos de mapeamento participativo pretendem dar voz a segmentos sociais subalternos, é preciso ter clareza em relação às estruturas de poder nas quais se inserem as experiências. Ao discutir o lugar dos mapas nas abordagens participativas, Joliveau enfatiza a pertinência da questão em face das assimetrias que os processos de mapeamento desencadeiam, seja por veicularem novos conhecimentos, seja por darem acesso a recursos tecnológicos e a conhecimentos tradicionais de forma inédita.

Pesquisas sobre "empoderamento, marginalização e participação pública” nos SIGs foram realizadas por pesquisadores americanos desde os primórdios da utilização das novas tecnologias. É, portanto, vasta a pauta de pesquisa para aqueles que têm se preocupado com os usos contemporâneos dos mapas, com as cartografias sociais e com os mapeamentos participativos cujo resultado promove a emergência de variadas territorialidades, as quais colorem, animam, concorrem ou se superpõem no grande mapa da nação. Neste sentido, é sugestivo o mosaico composto por imagens de cartografias sociais, mapeamentos etnoecológicos, mapeamentos culturais, mapeamentos participativos ou diagnósticos ambientais que ilustram a capa do livro Cartografias sociais e território.

A discussão sobre o potencial heurístico e as implicaçôes sociais do uso das tecnologias junto às populações e ao planejamento territorial vem se desenvolvendo desde os anos 1990 fora do Brasil, como indicam os artigos de Albertus Pramono, Eric Sheppard, Jacques Lévy, Jeremy W. Crampton, John Kryiger, Krusnawati Surinata, Luis Régis Coli, Peter Hershok e Thierry Joliveau. Ainda assim, Sheppard considera ser reduzida a reflexão sobre os processos desencadeados pela utilização do SIG crítico, seja do ponto de vista dos planejadores, seja na perspectiva dos sujeitos sociais envolvidos em trabalhos, programas e projetos que se favorecem das tecnologias de mapeamento.

A observação estende-se ao caso brasileiro em que é especialmente reduzida a reflexão feita por geógrafos e/ou cartógrafos em relação à discussão teórico-metodológica vinculada ao uso dos SIGs e das novas tecnologias em projetos de mapeamento participativo ou do uso das cartografias sociais. Tal ausência é mais significativa por não ser correlata à crescente demanda e efetiva atuação de profissionais de geografia com domínio das novas tecnologias de informação geográfica. 
Considero a coletânea um estímulo à reflexão sobre as diferentes experiências relacionadas a processos cartográficos no Brasil, assim como ao debate crítico sobre os usos das novas tecnologias, seus impasses e estratégias utilizadas em situaçôes particulares de mapeamento. Tais contribuições certamente serão profícuas para o equacionamento dos desafios que os processos de cartografia contemporâneos trazem. Além do reconhecimento do território comum - questão de fundamental interesse na solução dos conflitos relacionados aos processos jurídicos de demarcação de terras e acesso aos recursos -, as potencialidades que as novas modalidades de cartografias participativas promovem são significativas, pois podem vir a revelar, de forma inédita, visões de mundo e marcadores simbólicos dos espaços pouco valorizados nas cartografias tradicionais, dando visibilidade a distintas modalidades de demarcação e aos usos sociais do espaço que processos democráticos ensejam.

\section{ESPAÇO PÚBLICO: DO URBANO AO POLÍTICO}

Sérgio Luís Abrahão

Ed. Annablume/Fapesp, 2008, $1^{\text {a ed. }}$

Sarah Feldman

Professora livre docente do Programa de Pósgraduação em Arquitetura e Urbanismo da EESC-USP

O livro Espaço Público: do urbano ao político, de Sérgio Luís Abrahão, traz importantes contribuições para o debate e a reflexão sobre o espaço público - tema que, nas últimas duas décadas, vem mobilizando múltiplos campos disciplinares. $\mathrm{O}$ argumento que estrutura o livro é a atribuição de uma dimensão política à materialidade dos espaços urbanos, que Abrahão detecta como elemento persistente nos trabalhos desenvolvidos na área de Arquitetura e Urbanismo.

$\mathrm{O}$ autor situa a origem desta articulação na análise crítica do urbanismo modernista formulada na década de 1950. É a partir desse momento que, em oposição ao "espaço racionalizado", as relaçôes sociais no espaço urbano são retomadas como valores positivos da vida urbana, e são mobilizados conceitos, métodos de interpretação do espaço e proposiçóes de urbanismo que levam à perspectiva do que o autor define como "uma forma de materializar no urbano o espaço político das sociedades democráticas" (p.177).

O autor historiciza a construção conceitual deste "espaço público político" a partir da interação de ideias formuladas no âmbito da filosofia, sociologia, antropologia, geografia com proposiçóes urbanísticas. $\mathrm{O}$ percurso delineado por Abrahão destaca três momentos de inflexão nesse processo. Os Congressos Internacionais de Arquitetura Moderna (CIAMs), quando as bases para as propostas de "centros cívicos" e para projetos que conferem às ruas o estatuto de lugares de encontro e de reunião da comunidade são introduzidas por Jose Luis Sert, Siegfried Giedion e por arquitetos do Team X Group, como Peter e Allison Smithson. Os anos de 1960, período em que os estudos de Jane Jacobs e de Henri Lefebvre, pautados na observação da vida social orgânica e espontânea de comunidades, assim como os métodos analíticos desenvolvidos por Aldo Rossi, reforçam esta perspectiva humanista das cidades. E o período mais recente, em que esta dimensão humanista dá lugar a uma dimensão política que inclui a totalidade do território urbano. A cidade passa a ser entendida como lugar cívico. Amplia-se, nesse momento, o leque de abordagens sobre o espaço público que destacam os impasses e a crise dos valores contemporâneos. Estudos realizados por Michel Brill, Sharon Zukin, Gilles Lipovetsky e Rosalyn Deutsche expressam esta diversidade, que Abrahão qualifica como "polifonia". Nestas formulações, ganham importância concepçôes de espaço público moldadas nos campos da filosofia e das ciências sociais, destacandose os trabalhos de Hanna Arendt, Jürgen Habermas e Richard Sennet.

Ao mesmo tempo em que recupera esta trama conceitual, Abrahão detecta sua repercussão em investigaçōes e em experiências de planejamento urbano desenvolvidas no Brasil. Mostra a mudança da abordagem da rua, na década de 1970, para uma abordagem do espaço público, na década de 1990, e a relação deste deslocamento a contextos políticos diversos - o período militar e o período democrático, respectivamente. Mostra, ainda, que nos estudos realizados nos últimos vinte anos, prevalece o debate sobre o chamado "recuo do espaço público", associado às mudanças na produção e na gestão do espaço urbano determinadas pelo neoliberalismo. 